\title{
Locating drainage tiles at a wetland restoration site within the Oak Openings region of Ohio, United States using UAV and land based geophysical techniques
}

\section{Anna M. Becker}

The University of Toledo College of Natural Sciences and Mathematics

\section{Richard H. Becker}

The University of Toledo College of Natural Sciences and Mathematics

Kennedy O. Doro ( $\square$ Kennedy.doro@utoledo.edu )

The University of Toledo College of Natural Sciences and Mathematics https://orcid.org/0000-00017498-7053

\section{Research Article}

Keywords: Drainage tiles, UAV, visible light, thermal infrared, ground penetrating radar

Posted Date: May 26th, 2021

DOl: https://doi.org/10.21203/rs.3.rs-442089/v1

License: (c) (i) This work is licensed under a Creative Commons Attribution 4.0 International License.

Read Full License

Version of Record: A version of this preprint was published at Wetlands on November 16th, 2021. See the published version at https://doi.org/10.1007/s13157-021-01495-6. 


\section{Abstract}

Drainage tiles were used to drain wetlands in the midwestern United States to convert them into farmlands. With decades of farm operations, utility maps showing tiles' locations are now mostly innaccurate or simply do not exist. However, knowledge of the location of tile networks is needed to effectively restore these farmlands to their original wetlands conditions. With many fields spanning several hectares, efficiently locating drainage tiles at large farmfields can be problematic. Drainage tiles create variations in soil physical properties including moisture content, surface temperature and dielectric permeativity within and around the pipes which can be sensed by geophysical methods. Our study assesses the application of electromagnetic radiation via visible and thermal infrared imaging using an unmanned aerial vehicle and ground penetrating radar (GPR) to locate drainage tiles at large farmfield scale. The study was conducted at the Sandhill Crane wetland, a $1.1 \mathrm{~km}^{2}$ old agricultural field located in Swanton, Ohio. A UAV equiped with visible and thermal infrared cameras acquired imagery on a regular grid and about $100 \mathrm{GPR}$ lines were measured using a $250 \mathrm{MHz}$ radar system. Both visible and thermal infrared images identified the drainage tiles and their orientations. GPR profiles reveal the drainage tiles mostly in a parallel East-West direction. By using a UTV to pull the GPR system, we efficiently collected data along long profiles covering the entire site. The delineated tile network will improve management of the anthropogenically altered hydrology at the site as it is being restored into its original wetland conditions.

\section{Introduction}

Drainage tiles have been extensively used in what was historically known as the Great Black Swamp in the Midwestern region of the United States since the late 1800s to drain excess water and lower the water table for settlement and related activities including farming (Andreas and Knoop, 1992; Kaatz, 1955). Detailed utility maps showing the location and depths of these tiles are in most cases missing due to poor land or farm management practices. In the absence of such maps, locating these drainage tiles by traditional probing using flexible metal rod and excavations are tedious and destructive (Ruark et al., 2009). The use of non-invasive techniques including vegetation analysis (Tlapáková et al., 2015), aerial photographs, remote sensing (Williamson et al., 2019) and geophysical methods such as ground penetrating radar (Allred et al., 2004; Chow and Rees, 1989; Koganti et al., 2020) if applicable, provide a more efficient approach for locating the tiles. This study further evaluates the use of both unmanned aerial vehicle (UAV)-based visible and thermal infrared imaging and land-based ground penetrating radar for locating drainage tiles and mapping their network at a large field scale within the Oak Openings Region of Northwestern Ohio.

Historically, Northwestern Ohio and part of Michigan and Indiana constituted a vast wetland refered to as the "Black Swamp" with its low lying lands partially or entirely covered with water in the winter and spring (Kaatz, 1955). This once vast wetland area has been largely drained to accommodate human settlements and farmlands leaving behind less than $5 \%$ of the earlier wetland area (Lenhart and Lenhart, 2014). In particular, the narrow region west of Toledo, Ohio which extends to the west of Michigan named the Oak 
Openings Region (OOR) provide a typical hydrological scenario requiring extensive drainage in order to farm its land (Shade and Valkenburg, 1975). The unique shallow stratigraphy of the Oak Openings Region of Northwestern Ohio consisting of medium to coarse grained sand underlain by low permeability, clay-rich glacial-lacustrine sediments and glacial till (Shade and Valkenburg, 1975) result in poorly drained saturated fields. These fields were extensively drained using drainage tiles to allow the cultivation of crops. Converting these wetland areas to farmlands relied on easily available technology for installing agricultural drainage tiles used to manage the excess water on the field (Gedlinske, 2014).

The material composition of drainange tiles, their structure and installation techniques have evolved over the years. Earlier tiles were either made of clay, wood, or concrete with a diameter of approximately $15 \mathrm{~cm}$ and approximately $30 \mathrm{~cm}$ long (Beauchamp, 1987). The tiles were typically placed end-to-end following a linear path in about 75-150 cm deep trenches either dug manually or by a trenching machine towed by a horse (Allred et al., 2005; Gedlinske, 2014; Yannopoulos et al., 2020). Since the 1960's, clay, wooden and concrete tiles have been replaced by corrugated plastic tubings (CPT) which are made of high-density polyethylene and perforated to allow for infilteration. These modern tiles are installed at depths ranging from $90 \mathrm{~cm}$ to $150 \mathrm{~cm}$ with spacing ranging from $10 \mathrm{~m}$ to $25 \mathrm{~m}$ depending on site conditions including soil type, slopes, surface conditions, and crops. Modern machines are able to complete the process of trenching, installation, and backfilling simultaneous allowing for easy installation. This has contributed to the intensive use of drainage tiles in the Midwestern United States (Allred et al., 2005; Yannopoulos et al., 2020).

While population growth, urbanization, and the need to increase food production made the use of drainage tiles very popular within Northwestern Ohio, it also resulted in the disappearance of wetlands within the region (Abella et al., 2001; Higgins, 2003; Kaatz, 1955). However, the recent desire to address lake eutrophication producing harmful algae blooms and the need to protect endeagered species within the Oak Opening regions has increased awareness for restoring lands within Northwest Ohio to their original wetland state. Most of the land being restored are old farm fields with a history of intense drainage using artificial agricultural drainage tile, and excessive runoff from these fields are identified as an important source of nutrient loading, specifically nitrogen and phosphorus associated with Harmful Algal Blooms (HABs) (Moore, 2016; Smith et al., 2015). Unfortunately, in most instances, the location and or depths of these drainage tiles are not well documented. Restoring old farmlands back to wetland conditions will require knowledge of the tile locations to allow decommissioning the tiles which involes blocking the tile outlets and sometimes digging them out. In cases involving blocking the tile outlet to retain water within the site, knowledge of the tile network is still necessary to manage potential hydrological hazards such as flooding and blow-out (Cooley and Herron, 2015; Easton et al., 2016). Hence, the need for an efficient approach for locating drainage tiles mostly at such farm field scale.

Drainage tiles can be located manually within a farm field using a traditional handheld probing rod (Allred et al., 2005) consisting of an approximately $0.8 \mathrm{~cm}$ stainless steel rod with a rounded, welded tip to help prevent puncturing the tile. Using the handheld probe rod is very tedious and unrealistic for large field scale application. Analysis of spatial distribution of vegetation cover (e.g. cover crops) could give 
overview of the tile network (Tlapáková et al., 2015). However, the high variability in other properties and processes controlling the spatial and temporal distribution of vegetation cover such as soil moisture, nutrient content, and evapotranspiration limit reliance on this approach (Naz et al., 2009). Geophysical methods including ground penetrating radar, magnetometry, aerial photographs, satellite-based, and other remote sensing teniques provide a non-invasive approach for locating drainage tiles and delineating their network (Allred et al., 2004; Rogers et al., 2005).

Aerial imagery using different wavelengths of reflected and emmitted electromagnetic energy including visible-color, near infrared and thermal infrared has been explored for mapping drainage tiles' locations (Abdel-Hady et al., 1970; Allred et al., 2020; Kratt et al., 2020; Williamson et al., 2019; Woo et al., 2019). Using these images relies on the contrast in reflection or emission of electromagnecitc energy between soils overlying the drainage tiles and the soils between them.

Field aerial imaging including visible, infrared, thermal and multispectral imaging for mapping drainage tiles' location and network can be done using traditional satellite platforms and aircrafts (Abdel-Hady et al., 1970; Gökkaya et al., 2017; Naz et al., 2009; Verma et al., 1996). Earlier studies have however shown that for the method to be effective, data acquisition should be preferably done around 2-3 days after a rain event with 1-2 cm of precipitation (Allred et al., 2020; Kratt et al., 2020). Scheduling a conventional aircraft targeting such favourable field conditions are challenging as airplanes may not be easily available under short notices (Allred et al., 2018; Allred et al., 2020). Recent studies have focused on using unmanned aerial vehicles (UAV) equipped with multiple cameras which provides the desired flexibility for acquiring these aerial images (Allred et al., 2020; Kratt et al., 2020; Williamson et al., 2019). Validatory studies mostly in the OOR are missing giving the dependence of these techniques on the spatial and temporally varing properties such as soil type, water content, and vegetation (Naz et al., 2009).

While remote sensing techniques have been useful in locating drainage tiles and mapping their network, they are limited in depth estimates of individual tiles and their success rate have also varied with field site conditions (Woo et al., 2019). Hence, the need to keep exploring the use of conventional ground-based geophysical techniques including magnetic gradiometry (Allred et al., 2004; Rogers et al., 2005) and ground penetrating radar (Chow and Rees, 1989). Ground penetrating radar (GPR) has been widely used to successfully locate drainage tiles and map their network relying on the contrast in the dielectric properties of the soil around the tile and that of the air, water or a combination of both within the tiles (Allred et al., 2005; Allred et al., 2004; Allred, 2013; Koganti et al., 2020; Wai-Lok Lai et al., 2018). Detecting drainange tiles using GPR is possible in a wide variety of soil types and properties with reported applications in fine and coarse loamy glacial till, sandy glaciofluvial and clayey glaciomarine sediments (Allred et al., 2004; Chow and Rees, 1989). Chow and Rees (1989) demonstrated a near $100 \%$ success rate in using GPR to delineate clay and plastic drainage tiles in soils developed in a glacio-fluvial deposits. Applications in about 14 test plots in southwestern, central and northwestern Ohio have also been reported with success rate ranging from 50-100 \% (Allred et al., 2004). The success rate depends on soil types, conditions and GPR antenna frequencies and configurations (Allred et al., 2005). While most of these studies where at small scale test sites, Allred et al. (2018) highlighted the need and 
presented a feasibility study accessing the practicality of using GPR to delineate drainage tiles at large field scale. They emphasized the need for integrating the GPR system with a differential global positioning system to map tile network at such large field scale.

Drainage tile detection research using non-invasive geophysical methods has shown variable effectiveness at field scale with the effectiveness depending on site specific conditions such as soil type, vegetation cover, and water saturation (Jazayeri et al., 2018). An average success rate of $72 \%$ has been reported within Northwest Ohio with a 50-50 chance reported in one of the studies (Allred et al., 2005). This shows the need for more case application studies. Also, no study or application have been reported within the Oak Openings Region of Ohio using geophysical techniques to locate drainange tile within its farmfields. With the current effort to restore multiple farmfields to their natural wetland conditions within th region, there is a need for validating the applicability of non-invasive geophysical methods for locating and mapping drainage tile networks within the region. This study investigates the use of visible and thermal infrared imaging as well as the use of ground penetrating radar for locating drainage tiles within the Oak Openings Region of Ohio with the aim of developing a detection method framework that is applicable at large field scale. The use of UAV equipped with different cameras as well as mapping from a GPR system equipped with a real time kinematic (RTK) GPS system allows a large scale spatial coverage to be assessed. Practical aspects including suitable GPR frequencies and transect spacing are also assessed in this study.

\section{Study Site}

This study was conducted at the Sandhill Crane wetland restoration project site of The Nature Conservancy (TNC) located at Angola Road in Swanton, Ohio (Fig. 1). The site was previously an agricultural field with an approximate area of $1.1 \mathrm{~km}^{2}(0.75 \mathrm{~km} \times 1.4 \mathrm{~km})$ and is currently being restored to a wet prarie (wetland) habitat. It has a relatively flat topography with elevation slope less than $2 \%$ and lower depressions at its western, eastern and north central segments. The site sits in the Oak Openings Region (OOR) in Northwestern Ohio, an important wet prairie ecosystem characterized by poorly drained shallow sandy soils underlain by glacial till (Shade and Valkenburg, 1975; Wijayarathne and Gomezdelcampo, 2019). The subsurface at the site is characterized by fine to medium grained sand from the top to depths of 3-5 m with high organic content at its top $0.35 \mathrm{~m}$ mostly in the eastern and western flank which are inundated during the spring (Becker et al., 2020). The sand at the site is part of the reworked sands deposited along the edges of ancient Lake Wane, Warren and Lundy by Lake Michigan long shore currents (Brewer and Vankat, 2004; Wijayarathne and Gomezdelcampo, 2019). Based on interpreted electrical resistivity data acquired as part of an ongoing study (Becker et al., 2020), the sands are underlain by glacial-lacustrine sediments and glacial till (with resistivity ranging from 40 to $120 \Omega \mathrm{m}$ ), which extends down to depth of $20 \mathrm{~m}$ and are followed by the bedrock (with resistivity ranging from from 120 to $250 \Omega \mathrm{m}$ ). The top sandy sediments are saturated with an average water table at a depth of $70 \mathrm{~cm}$ which varies seasonally. 


\section{Methods}

For this study, we utilized an unmaaned aerial vehicle (UAV) platform for both the visible and thermal infrared imaging while ground penetrating radar (GPR) measurements were conducted with GPR antennas mounted on a cart to ease data acquisition. We also towed the GPR system behind a utility terrain vehicle to enable us cover our large farm field scale site.

\section{Visible and Thermal Infrared Imaging}

Remote sensing techniques using electromagnetic (EM) radiation with wavelengths within the visible and infrared spectrum have been used to locate subsurface drainage pipes (Allred et al., 2020; Kratt et al., 2020; Naz et al., 2009). Visible light imaging involves the use of cameras capable of sensing EM radiation with wavelengths ranging from $400 \mathrm{~nm}$ to $700 \mathrm{~nm}$ visible to the human eye. Contrast between water content in soil above a drainage pipe and that between the pipes results in variability of reflectance in the visible light region. Increase in the reflected light produces a lighter shaded linear surface feature characteristic of a drainage pipe (Allred et al., 2020). Thermal infrared imaging on the other hand involves sensing EM radiation within the short wave infrared spectrum ranging from $900 \mathrm{~nm}$ to $14,000 \mathrm{~nm}$. Based on the differences between the specific heat capacity of water and soil materials and as a result, thermal inirtia, the soil above a drainage pipe also show temperature contrast compared to its surrounding due to differences in water content. This creates a contrast in the thermal radiation between the soil above the drainage pipe compared to its surrounding following the Stefan-Boltzmann and Kirchhoff's laws (Allred et al., 2020; Woo et al., 2019). This contrast can be observed in a thermal infrared image and provide insight to the location and network of drainage pipes. Both visible and infrared imaging can be conducted using aerial platforms including unmanned aerial vehicle with the advantage of large spatial coverage within a short time.

For this study, we utilized a visible color camera and a FLIR Vue Pro thermal imager mounted on a DJI Phantom 3 Pro UAV. The FLIR Vue Pro imager has a 640 . 480 sensor array, with a $13 \mathrm{~mm}$ optic, giving a 25 degree field of view (FOV) recording thermal imagery at $30 \mathrm{~Hz}$. The Phantom 3 Pro has a $4000 \cdot 3000$ Red, Green and Blue (RGB) visible light camera with a $20 \mathrm{~mm}$ lens, giving a 94 degree FOV. Flights were conducted under Federal Aviation Administration regulations - FAA part 107 rules. The flights were conducted between May and June, 2020 on a regular grid at 50 or 100 feet above groud level, based on local airspace restrictions from the Toledo Express airport control. RGB imagery was processed in Agisoft Metashape to generate a composite orthomosaic of the field sections flown. Thermal imagery was referenced against the RGB orthomosaic.

\section{GPR Data Acquisition and Processing}

GPR is a well-established geophysical technique and has been used to locate utilities (Lester and Bernold, 2007; Metwaly, 2015; Wai-Lok Lai et al., 2018) within the shallow subsurface including agricultural tile drainage (Allred et al., 2005; Allred et al., 2004; Allred, 2013; Chow and Rees, 1989). The technique involve the emission of electromagnetic (radar) pulses by a transmitting antenna which are reflected, scattered and attenuated depending on the subsurface properties including its dielectric permittivity and 
conductivity as the radar pulses travel through it (Chow and Rees, 1989; Jazayeri et al., 2018). Refelected radar signals eventually travel to the surface where they are recorded by a receiving antenna to produce a signal trace which reflects changes in the wave amplitude and energy with time (Allred et al., 2005). A buried cylindrical pipe such as a drainage tile generates a characteristic diffraction hyperbola due to its shape, the spherical nature ot the wave front and contrast between the dielectric properties of the air and or water inside the pipe and that of the sorrounding soil (Allred et al., 2005; Chow and Rees, 1989; Jazayeri et al., 2018). The diffraction hyperbolas of pipes in GPR profiles are clearly distinctive such that they can be displayed and interpreted in real time making GPR a widely used technique for real time location of subsurface utilities.

For this study, we utilized the Sensors and Software, Inc. (Mississauga, ON, Canada) PulseEkko systems which are bistatic radar systems with the transmitter and receiver separated into different units. We first tested systems with antenna frequencies of $50,100,200$ and $250 \mathrm{MHz}$ in a rough sweep of the site to acess which is suitable for locating the drainange tile network. We later utilized the $250 \mathrm{MHz}$ antenna with a fixed transmitter and receiver antenna separation of $0.4 \mathrm{~m}$ for surveying the entire site. We towed the GPR system consisting of the antennas and a DVL 500 data logger behind a utility terrain vehicle to allow us cover the entire site of approximately $1.1 \mathrm{~km}^{2}$. We also utlilized 2 units of an Emlid Reach RS2 differential GPS system (Emlid Ltd, Hong Kong.) for a real time kinematic (RTK) positioning with one positioned at a fixed base while the other was attached to the GPR system as a rover. We acquired GPR transects in both the North - South and the East - West directions (Fig. 2) to better capture potential tiles running in different directions. We maintained a spacing of $20 \mathrm{~m}$ between transects in the North-South direction and $25 \mathrm{~m}$ for transects in the East - West direction. We collected common-offset measurements with a spacing of $0.05 \mathrm{~m}$, activated by an odometer wheel attached to a towing cart with an acquisition time window of $100 \mathrm{~ns}$. To reduce ambient electromagnetic noise and improve signal to noise ratio, we collected 4 stacks per sample and towed the GPR system at an average speed of 6.5 kilometers per hour following recommendations by Allred et al. (2005). A major challenge in using GPR to locate drainage tiles at a large field scale is the choice of an appropriate transect spacing to adequately delineate the tile network. For this study, we assess the impact of transect spacings on resolving the tile nework by conducting different small suveys within the field with transect spacing of $2.5,5,10$ and $20 \mathrm{~m}$.

All GPR data were processed using the Sensors \& Software Inc.'s EKKO_Project software following standard GPR processing for subsurface utility identification (Annan, 2009; Jazayeri et al., 2018). We applied a time-zero correction and then 'dewowed' the signals with a high-pass filter to remove lowfrequency noise caused by inductive coupling effects or dynamic range limitations of the antennas (Annan, 2009; Malenda et al., 2019). We applied a Spherical Exponential Calibrated Compensation (SEC 2) time gain to all transects' signals to compensate for signal losses due to spherical spreading and ohmic losses caused by soil conductivity. We set the signal attenuation at $8 \mathrm{~dB} / \mathrm{m}$ to increase gains for deeper signals while start and maximum gains were set at 4.5 and 1000 respectively. To estimate the depth of the tiles, we utlize the velocity caliberation approach following the hyperbola fitting technique (Dou et al., 2017; Sagnard and Tarel, 2016) implemented in the Ekko_Project version 5 software. 
After applying the outlined processing steps to the GPR datasets, we interpreted each profile for the presence of a characteristic hyperbola indicating possible drainage tile. We picked the peak of each hyperbola to represent the center of the drainage tile assuming that the GPR system crossed the tile perpendicularly. By plotting the center of each hyperbola on a map we were able to delineate the drainage tile network.

\section{Results}

Visible light images (Fig. 3a) obtained for our study site show color patches with contrasting light and dark colors stripes reflective of variation in soil condition and vegetation. The light colored, close stripes linear features are related to tillage lines while the dark green green parallel linear features with a near uniform spacing were interpreted as drainage tiles. The dark green parallel linear features were also observable to the naked eye in the field as stripes with more greenish (healthy) cover crops preferentially lined along a straight path. When traced (Fig. 3b), these parallel linear features shows a consistent spacing of about $15 \mathrm{~m}$ which is typical of spacing between drainage tiles in the field in the region (Gedlinske, 2014). The identified stripes (interpreted as drainage tiles) are discontinuous in some area or at least difficult to identify.

Thermal infrared images of the study site are shown in Fig. 4 with closely spaced red, yellow and blue color stripes with dull color stripes cutting across them. In the color table used in these images, brighter colors in the false color thermal infrared images are indicative of warmer areas while dull or darker colors are indicative of cooler areas. Drainage tiles due to their water content are cooler and are expressed as dull color linear structure in the infrared image (Fig. 4). Figure 4 (left image) show two linear dull color parallel feature with one of them imaged at a high resolution (Fig. 4 right) interpreted as drainage tiles.

Representative gpr profiles from transects both in the N-S and E-W directions are shown in Fig. 5. Concave upward hyperbolas are observed in each of the profile at an approximate depth of $1.0 \mathrm{~m}$. The hyperbolas interpreted as the top center point across a drainage tile (when crossed perpendicularly) are in most cases spaced evenly at an approximate distance of $15 \mathrm{~m}$. All GPR profiles (sixty-six in the N-S direction and thirty-one in the E-W) were carefully analyzed and the position of all hyperbolas highlighted with their coordinates and depths. We exported these details to a google earth map (Fig. 6) to show the location where the GPR system crossed possible drainage tiles with blue dots for profiles in the N-S direction and pink for profiles in the E-W direction (Fig. 6). Although hyperbolas in GPR profiles could also result from other subsurface objects e.g. pebble with contrasting dielectric permeativity, similar hyperbolas allinging along a trend in parallel profiles are interpreted as a linear feature which in this case would represent a drainage tile. We joined similar hyperbolas with yellow lines (Fig. 7) for profiles running $\mathrm{N}-\mathrm{S}$ and orange lines (Fig. 7) for profiles running E-W to obtain the position and network of drainage tiles in the field.

\section{Discussion}


The delineated drainage tiles at the study site follows a parallel pattern with a spacing between tiles of 15 $\mathrm{m}$ (Fig. 7). Tiles alligned in the E-W direction are present in the Eastern, Western and North Central portion of the site corresponding to areas observed to be flooded in the spring. The tiles in these regions were likely installed and connected to pumps located both at the eastern and western segments to drained these section of the field during flooding to allow farming activities (oral communication with neighboring farmers at the site). Transects acquired in the E-W direction at the Eastern half of the site also show tiles aligned North - South close to the center and at the upper right of the site (Fig. 7). These tile lines are likely feeder lines connected to the tile lines aligned East - West. Our study shows that for field sites with no prior knowledge of the tile network, acquiring the GPR transects in both North - South and East - West directions is more appropriate. This though increases the field efforts, ensures that the tile network is captured appropriately. Delineated drainage tile lines shown in Fig. 7 show discontinuities which are areas where no hyperbola was observed in the GPR profile or they were difficult to be identified. This could be due to broken tiles or low contrast in dielectric properties between the tile and surrounding soil. The tiles are expected to have been installed following a near straight path.

Generally the visible and thermal infrared images captures the location and trend of the drainage tiles with the thermal infrared images providing clearer contrast related to the tiles. However, discontinuities in the identified tile lines were noted more in the visible images compared to the thermal infrared. Factors including vaying soil water, vegetation, ambient temperature, and evapotranspiration influence the reflectance and radiation of electromagnetic wave hence affect measurements (Allred et al., 2018; Allred et al., 2020; Kratt et al., 2020). Despite these limitation, both visible and thermal infrared imaging sufficiently imaged the tiles at our test site. The possibility to mount these cameras simultaneously on a UAV allow for fast acquisition of multiple data sets. However, because registering and mosaicing thermal images is more time consuming and problematic than processing visible images, and the precise locations from thermal imagery are not as reliable as the other methods, significant post proceesing effort would be needed to extract and align acquired thermal images. While each of these techniques can be used independently we recommend combining them to improve results and maximize data value. Compared to the GPR technique, the UAV based visible and infrared imaging allows for coverying large scale field sites within a short time. However, GPR technique provide a highly accurate location of the tiles both horizontally and vertically (Figs. 5, 7 and 8) allowing a good estimation of the depth at which the tiles are buried. While UAV based methods possess clear advantage over land based geophysical method in terms of data acquisition time, for open fields (e.g. during post havest seasons), towing the GPR with a UTV at a speed of approximately $6.5 \mathrm{Km} / \mathrm{h}$ significantly reduced data acquisition time.

In using GPR to locate drainage tiles, the choice of antenna frequency is not trivial as this in combination with soil properties and vegetation impact the resolution and ease of data acquisition. In this study, we compared four different Sensors and Softwares, Inc.'s PulseEkko antennas with center frequencies of 50 $\mathrm{MHz}, 100 \mathrm{MHz}, 200 \mathrm{MHz}$ and $250 \mathrm{MHz}$. Both $250 \mathrm{MHz}$ and $200 \mathrm{MHz}$ antennas clearly captures the hyperbolas representing the point where we crossed the drainage tile (Fig. 8). Although, the $250 \mathrm{MHz}$ antenna data show higher resolution, all tiles located by it where also resolvable by the $200 \mathrm{MHz}$ antenna in this study. The $100 \mathrm{MHz}$ antenna also captured over $80 \%$ of drainage tiles detected with the $250 \mathrm{MHz}$ 
and $200 \mathrm{MHz}$ antennas. While $60 \%$ of the tiles located by the $250 \mathrm{MHz}$ antenna are also identifiable in the GPR profile acquired with the $50 \mathrm{MHz}$ antenna, the hyperbolas appear blurred which would make interpretations difficult in areas with no prior information on the location of the tiles. Also, the $50 \mathrm{MHz}$, $100 \mathrm{MHz}$ and $200 \mathrm{MHz}$ PulseEkko GPR antennas are unshielded which makes it more challenging (mostly the $50 \mathrm{MHz}$ and $100 \mathrm{MHz}$ antennas which are over $0.5 \mathrm{~m}$ long) to tow over vegetated fields. Based on resolution and ease of field measurement, we recommend using the $250 \mathrm{MHz}$ shielded antennas where possible for measurements within the OOR or areas with similar soil properties and conditions. However, $200 \mathrm{MHz}$ and $100 \mathrm{MHz}$ antennas may be used but with caution during field data acquisition and more attention to processing and interpretations.

The choice of spacing between field GPR transects was also assessed by comparing measurements using spacing of 2.5, 5.0, 10.0, $20 \mathrm{~m}$ and $25 \mathrm{~m}$ at a small section of our field site. Measurements with transects spacing of 10,20 and $25 \mathrm{~m}$ sufficiently delineated the drainage tile network at our test site but their amplitude maps show smearing effect due to the larger interpolation distance between lines. GPR amplitude maps are used to show correlation in the 2D distribution of the amount of electromagnetic radar energy reflected back to the surface from a two - way travel time (Allred, 2013). GPR amplitude maps are useful in confirming the drainage tile network (Karásek and Nováková, 2020). In our study, amplitudes maps generated from grid measurements using both $2.5 \mathrm{~m}$ and $5 \mathrm{~m}$ spacing between transects in the $\mathrm{x}$-and y-directions in a $100 \mathrm{~m} \times 100 \mathrm{~m}$ domain at the eastern section of our site reveal the tile network (Fig. 9). The stronger applitude represented by dark coloration are stronger refelected energies (amplitudes). Grid with $5 \mathrm{~m}$ transects spacing sufficiently capture the tile network and is recommended.

Results of this study validate earlier results showing the use of UAV mounted visible and thermal infrared (Allred et al., 2020) and ground penetrating radar (Allred et al., 2004) for locating drainage tiles and demonstrates that these techniques can be used within the Oak Openings Region. We however, recommend further testing of the visible and themal infrared imaging under different seasons and soil conditions including varying soil water content, vegetation cover and time of day.

The location and network of drainage tiles delineated in this study will guide current efforts to restore the site from an old agricultural field to its original wetland (wet prairie) conditions. Figure 7 in a digitized form will guide site managers in locating tile outlets for decommissioning (blocking to prevent outflow). The site's drainage tile location map (Fig. 7) will also be useful in the future in locating individual tiles should there be need to block such tiles due to potential blow-out resulting from blockage of tile outlets. There is also the need to improve understanding of the site's hydrology which has been largely altered by the artificial tile drainage and intense farming. Results of this study also provides location and depth of tiles that can be included in a groundwater flow and transport model for predicting the hydrological respose (including potential flooding and flow redistribution) due to drainage tiles decommissioning and other restoration activities. 


\section{Conclusions}

Pre-restoration wetland characterization sometimes require knowing the locations and depths of drainage tiles mostly where the restored site is an old agricultural field with a history of tile drainage as commonly encountered in the Midwestern United States. When farm utility maps showing the tile locations are missing as in most cases, locating these tiles manually is impracticable at farm field scale. Our study show that combing remote sensing and ground based geophysical techniques provide an efficient framework for locating the tiles.

In this study, we used visible light and infrared imaging to locate drainage tiles and map their network within the Oak Openings Region of Ohio. Mounting the appropriate cameras on a UAV platform allows for fast data acquisition which can be used to cover large scale field site within a short duration. We observe discontinuities in interpreted drainange tiles from both visible and thermal infrared images which can be related to effect of varying moisture content and vegetation type. Targeting optimum filed conditions for visible and thermal infrared imaging for locating drainage tiles to minimize these effects is a major challenge and require further testing at sites with different soil, vegetation and hydrological properties.

Our study also shows ground penetrating radar to be a more effective geophysical technique for obtaining details of drainage tiles' location and depth mostly within the Oak Openings Region. This is in line with other studies at sites with similar soil properties within the Midwestern United States (Allred et al., 2005; Allred et al., 2004). However, for large field scale application, we recommend towing the GPR behind a vehicle at a speed of about $7 \mathrm{Km} / \mathrm{h}$ to reduce field effors and data acquisition times. For large field scale application as demonstrated in this study, a profile spacing of $20 \mathrm{~m}$ reveals tile location and network reasonably with a trade off on amplitude maps which are useful for confirming the tile network at a high resolution. Where such is desired, a maximum profile spacing of $5 \mathrm{~m}$ is recommended.

This study generally shows that geophysical sensing using suites of electromagnetic radiation (visibe, infrared and radio waves) provides non invasive approaches for locating drainage tiles in old farmfields within the OOR. With current wetland restoration efforts within Ohio aimed at reducing nutrient loads into Lake Erie, there is need to locate drainage tiles within these old farm field and this study demonstrate the application of geophysical techniques for such purpose. Delineated drainage tile network (Fig. 7) can be incorporated into a flow and transport model for the site and will be useful for predicting post-restoration hydrological regimes.

\section{Declarations}

\section{Acknowledgement}


The authors are grateful to Amar Kolapkar and Washington Mcgilvery for their support with field data acquisition. We also appreciate Alexis Sakas of the The Nature Conservancy for her support and The Nature Conservancy for allowing us use their property and project site for this study. Mark Dilley and his team at the MAD Scientist Associate are also acknowledge for their support and feedback on results of this study. Financial support by the Office of Undergraduate Research (OUR), University of Toledo, Ohio and the Ohio Sea Grant are also acknowledged.

Funding: This research was funded by the Ohio Sea Grant through the Small Grant Sea Grant project number R/ER-151-PD and the University of Toledo office of undergraduate research.

Conflict of Interest/Competing interests: The authors have no conflict of interest to declare

Ethics approval: Ethics approval was not required for this study according to the University of Toledo research ethics policy and the Ohio State legislation

Consent to participate: Not applicable as this study does not involve human subjects

Consent for publication: All authors gave consent to publish results of this work. The study does not involve patients and human subjects hence to consent required.

Availability of data and material (data transparency): The raw datasets acquired and analysed during the current study are available from the corresponding author on reasonable request.

Code availability: Not applicable

Authors' contributions: $\mathrm{AMB}$ is an undergraduate student researcher who acquired and analyzed the data and wrote the initial draft of the manuscript as part of her honors thesis. RHB acquired and analyzed the UAV based data and reviewed the manuscript prior to submission while KOD developed the research ideas, acquired and analysed data, wrote manuscript and supervised AMB.

\section{References}

Abdel-Hady, M., Abdel-Hafez, M.A. and Karbs, H.H. 1970. Subsurface drainage mapping by airborne infrared imagery techniques. Proc. Okla. Acad. Sci 50, 10 - 18.

Abella, S., Jaeger, J., Gehring, D., Jacksy, R., Menard, K. and High, K. 2001. Restoring Historic Plant Communities in the Oak Openings Region of Northwest Ohio. Ecological Restoration 19, 155-160.

Allred, B., Daniels, J., Fausey, N.R., Chen, C.-C., Peters, L. and Youn, H. 2005. Important considerations for locating buried agricultural drainage pipe using ground penetrating radar. Applied Engineering in Agriculture 21.

Allred, B., Eash, N., Freeland, R., Martinez, L. and Wishart, D. 2018. Effective and efficient agricultural drainage pipe mapping with UAS thermal infrared imagery: A case study. Agricultural Water Management 
Allred, B., Fausey, N.R., Peters, L., Chen, C.-C., Daniels, J. and Youn, H. 2004. Detection of buried agricultural drainage pipe with geophysical methods. Applied Engineering in Agriculture 20.

Allred, B., Martinez, L., Fessehazion, M.K., Rouse, G., Williamson, T.N., Wishart, D., Koganti, T., Freeland, R., Eash, N., Batschelet, A. and Featheringill, R. 2020. Overall results and key findings on the use of UAV visible-color, multispectral, and thermal infrared imagery to map agricultural drainage pipes. Agricultural Water Management 232, 106036.

Allred, B.J. 2013. A GPR Agricultural Drainage Pipe Detection Case Study: Effects of Antenna Orientation Relative to Drainage Pipe Directional Trend. Journal of Environmental and Engineering Geophysics 18(1), 55-69.

Andreas, B. and Knoop, J. 1992. 100 Years of Changes in Ohio Peatlands. The Ohio Journal of Science 92, 130-138.

Annan, A.P. (2009) Ground Penetrating Radar Theory and Applications. Jol, H.M. (ed), pp. 1-40, Elsevier, Amsterdam.

Beauchamp, K.H. (1987) Farm drainage in the United States. History, Status, and Prospects. Pavelis, G.A. (ed), p. 185, Economic Research Service (DOA), Washington, D.C.

Becker, A.M., Becker, R.H. and Doro, K.O. 2020 Pre-restoration Shallow Subsurface Characterization of a Wetland in the Oak Openings Region, Ohio Using Drone- and Land-based Geophysical Techniques., American Geophysical Union, Virtual.

Brewer, L.G. and Vankat, J.L. 2004. Description of Vegetation of the Oak Openings of Northwestern Ohio at the Time of Euro-American Settlement. Ohio J Sci 104, 76 - 85.

Chow, T.L. and Rees, H.W. 1989. Identification of subsurface drain locations with ground-penetrating radar. Canadian Journal of Soil Science 69(2), 223-234.

Cooley, E. and Herron, C. 2015 Fixing Tile Blowouts: What You Need to Know, UW Extension University of Wisconsin-Extension, Pigeon Falls, Wl.

Dou, Q., Wei, L., Magee, D.R. and Cohn, A.G. 2017. Real-Time Hyperbola Recognition and Fitting in GPR Data. IEEE Transactions on Geoscience and Remote Sensing 55(1), 51-62.

Easton, Z.M., Bock, E. and Collick, A.S. 2016 Factors When Considering an Agricultural Drainage System, Communications and Marketing, College of Agriculture and Life Sciences, Virginia Tech, Blacksburg, VA.

Gedlinske, B.B. 2014. Agricultural Drainage Tiles: An Overview of their Use, Benefits, and effect on Hydrology and Water Quality. Other Faculty and Staff Publications. 
https://scholarworks.uni.edu/other_facpub/1 1.

Gökkaya, K., Budhathoki, M., Christopher, S.F., Hanrahan, B.R. and Tank, J.L. 2017. Subsurface tile drained area detection using GIS and remote sensing in an agricultural watershed. Ecological Engineering $108,370-379$.

Higgins, J.B. 2003. Emergy analysis of the Oak Openings region. Ecological Engineering 21(1), 75-109. Jazayeri, S., Klotzsche, A. and Kruse, S. 2018. Improving estimates of buried pipe diameter and infilling material from ground-penetrating radar profiles with full-waveform inversion. GEOPHYSICS 83(4), H27$\mathrm{H} 41$.

Kaatz, M.R. 1955. The black swamp: A study in historical geography. Annals of the Association of American Geographers 45(1), 1-35.

Karásek, P. and Nováková, E. 2020. Agricultural Tile Drainage Detection within the Year Using Ground Penetrating Radar. Journal of Ecological Engineering 21(4), 203-211.

Koganti, T., Van De Vijver, E., Allred, B.J., Greve, M.H., Ringgaard, J. and Iversen, B.V. 2020. Mapping of Agricultural Subsurface Drainage Systems Using a Frequency-Domain Ground Penetrating Radar and Evaluating Its Performance Using a Single-Frequency Multi-Receiver Electromagnetic Induction Instrument. Sensors (Basel) 20(14), 3922.

Kratt, C.B., Woo, D.K., Johnson, K.N., Haagsma, M., Kumar, P., Selker, J. and Tyler, S. 2020. Field trials to detect drainage pipe networks using thermal and RGB data from unmanned aircraft. Agricultural Water Management 229, 105895.

Lenhart, C.F. and Lenhart, P.C. 2014. Restoration of Wetland and Prairie on Farmland in the Former Great Black Swamp of Ohio, U.S.A. Ecological Restoration 32(4), 441-449.

Lester, J. and Bernold, L.E. 2007. Innovative process to characterize buried utilities using Ground Penetrating Radar. Automation in Construction 16(4), 546-555.

Malenda, H.F., Sutfin, N.A., Guryan, G., Stauffer, S., Rowland, J.C., Williams, K.H. and Singha, K. 2019. From Grain to Floodplain: Evaluating heterogeneity of floodplain hydrostatigraphy using sedimentology, geophysics, and remote sensing. Earth Surface Processes and Landforms 44(9), 1799-1815.

Metwaly, M. 2015. Application of GPR technique for subsurface utility mapping: A case study from urban area of Holy Mecca, Saudi Arabia. Measurement 60, 139-145.

Moore, J. 2016 Literature Review: Tile Drainage and Phosphorus Losses from Agricultural Land, Lake Champlain Basin Program and New England Interstate Water Pollution Control Commission, Grand Isle, VT. 
Naz, B.S., Ale, S. and Bowling, L.C. 2009. Detecting subsurface drainage systems and estimating drain spacing in intensively managed agricultural landscapes. Agricultural Water Management 96(4), 627-637.

Rogers, M., Cassidy, J. and Dragila, M. 2005. Ground-based magnetic surveys as a new technique to locate subsurface drainage pipes: A case study. Applied Engineering in Agriculture 21.

Ruark, M.D., Panuska, J.C., Cooley, E.T. and Pagel, J. 2009. Understanding and Locating Tile Drainage Systems. University of Wisconsin-Extension Discovery-Farms Fact Sheet GWQ 054.

Sagnard, F. and Tarel, J.-P. 2016. Template-matching based detection of hyperbolas in groundpenetrating radargrams for buried utilities. Journal of Geophysics and Engineering 13(4), 491-504.

Shade, J.W. and Valkenburg, N. 1975. Comparison of the base flow and groundwater chemistry, Oak Openings Sand, Lucas County, Ohio. The Ohio Journal of Science 75(3), 138.

Smith, D., King, K. and Williams, M. 2015. What is causing the harmful algal blooms in Lake Erie? Journal of Soil and Water Conservation 70, 27A-29A.

Tlapáková, L., Žaloudík, J., Kulhavý, Z. and Pelíšek, I. 2015. Use of Remote Sensing for Identification and Description of Subsurface Drainage System Condition. Acta Universitatis Agriculturae et Silviculturae Mendelianae Brunensis 63, 1587-1599.

TNC 2020 The Sandhill Crane Wetland Project Series. Part 2: Hydrologic connections, The Nature Conservancy, Online.

Verma, A.K., Cooke, R.A. and Wendte, L. 1996 Mapping subsurface drainage systems with color infrared aerial photographs, pp. 457 - 466, American Water Resources Association Ft. Lauderdale, Florida.

Wai-Lok Lai, W., Dérobert, X. and Annan, P. 2018. A review of Ground Penetrating Radar application in civil engineering: A 30-year journey from Locating and Testing to Imaging and Diagnosis. NDT \& $E$ International 96, 58-78.

Wijayarathne, D.B. and Gomezdelcampo, E. 2019. Using shallow groundwater modeling to frame the restoration of a wet prairie in the Oak Openings Region, Ohio, USA: GSSHA model implementation. Environmental Earth Sciences 78(6), 216.

Williamson, T., Dobrowolski, E.G., Meyer, S.M., Frey, J. and Allred, B. 2019. Delineation of tile-drain networks using thermal and multispectral imagery-Implications for water quantity and quality differences from paired edge-of-field sites. Journal of Soil and Water Conservation 74, 1-11.

Woo, D.K., Song, H. and Kumar, P. 2019. Mapping subsurface tile drainage systems with thermal images. Agricultural Water Management 218, 94-101. 
Yannopoulos, S.I., Grismer, M.E., Bali, K.M. and Angelakis, A.N. 2020. Evolution of the Materials and Methods Used for Subsurface Drainage of Agricultural Lands from Antiquity to the Present. Water 12(6), 1767.

\section{Figures}

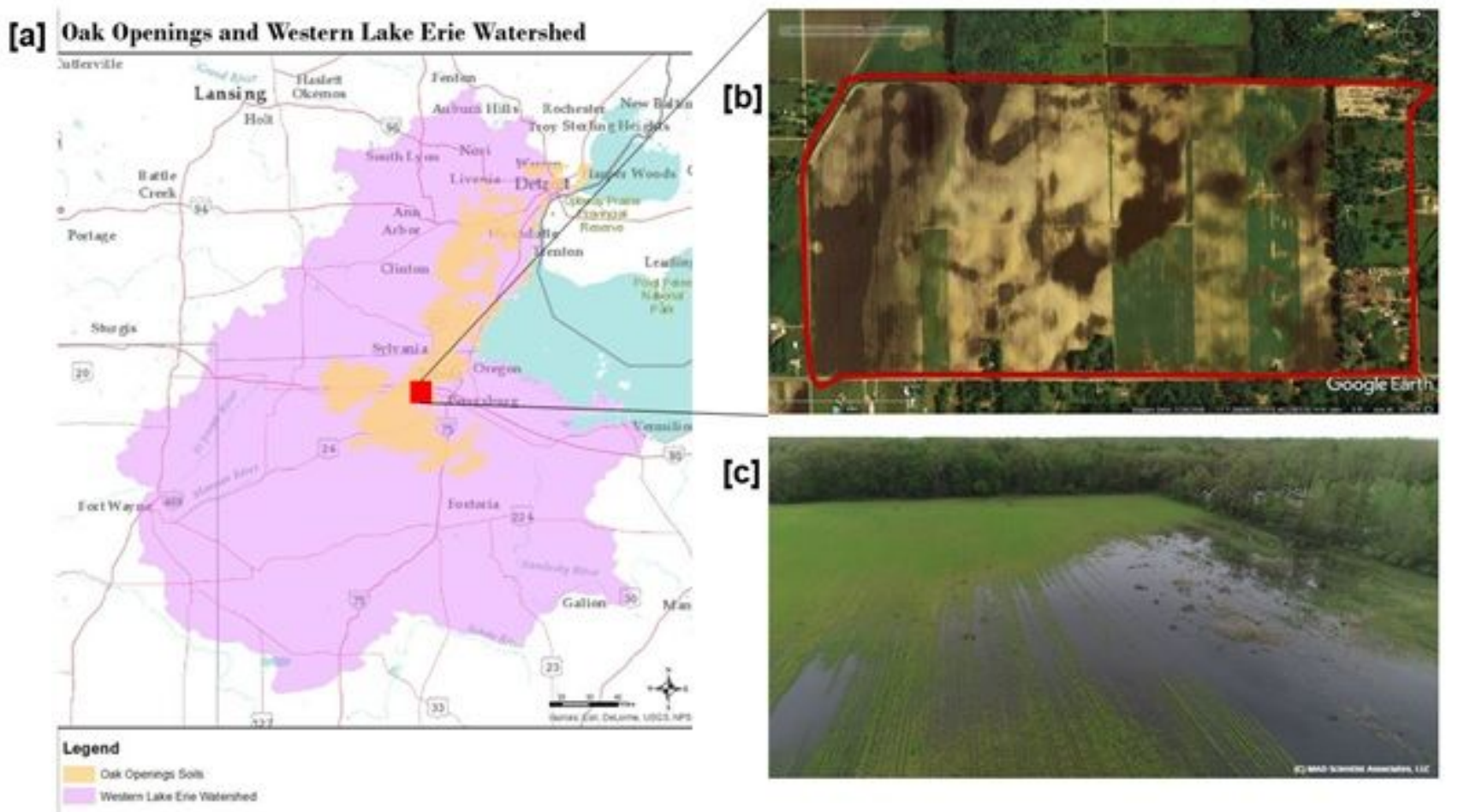

\section{Figure 1}

[a] Location of the study site within the Oak Openings region in Ohio, USA, [b] aerial photo of the site from google earth (Google Earth, earth.google.com/web), and [c] photo of site in early spring with edges flooded. Modified after (TNC, 2020). 


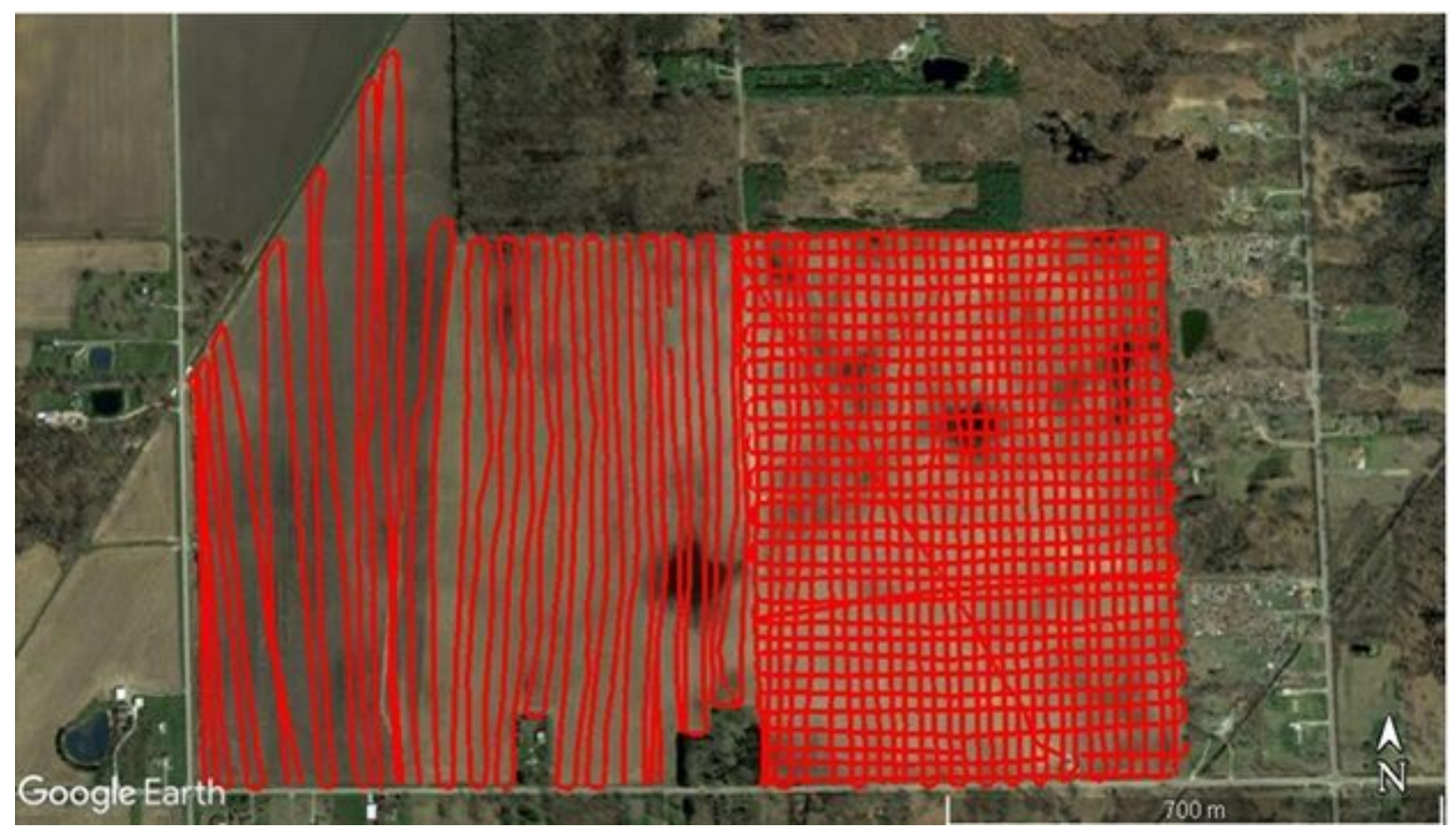

\section{Figure 2}

Study site with GPR transects both in the North - South direction and the East - West direction overlain with a google map (Google Earth, earth.google.com/web) of the study site. 
[a]

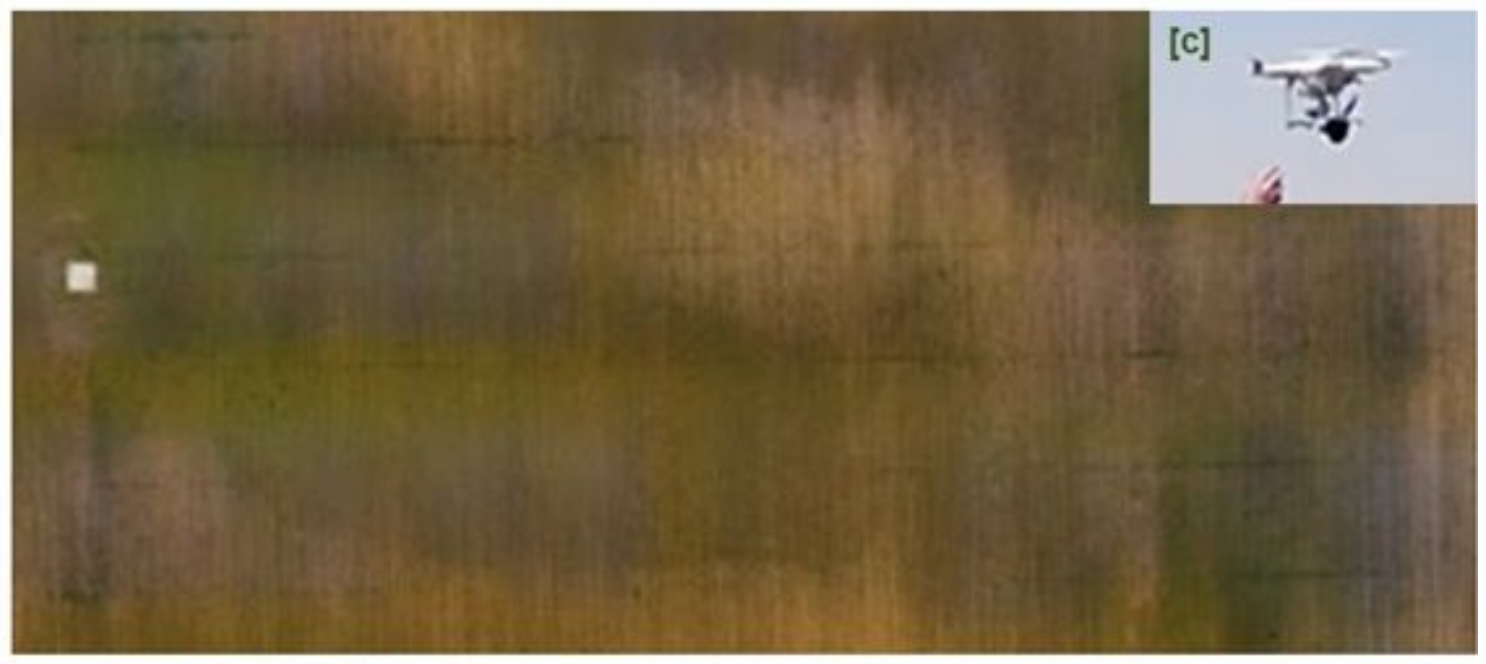

[b]

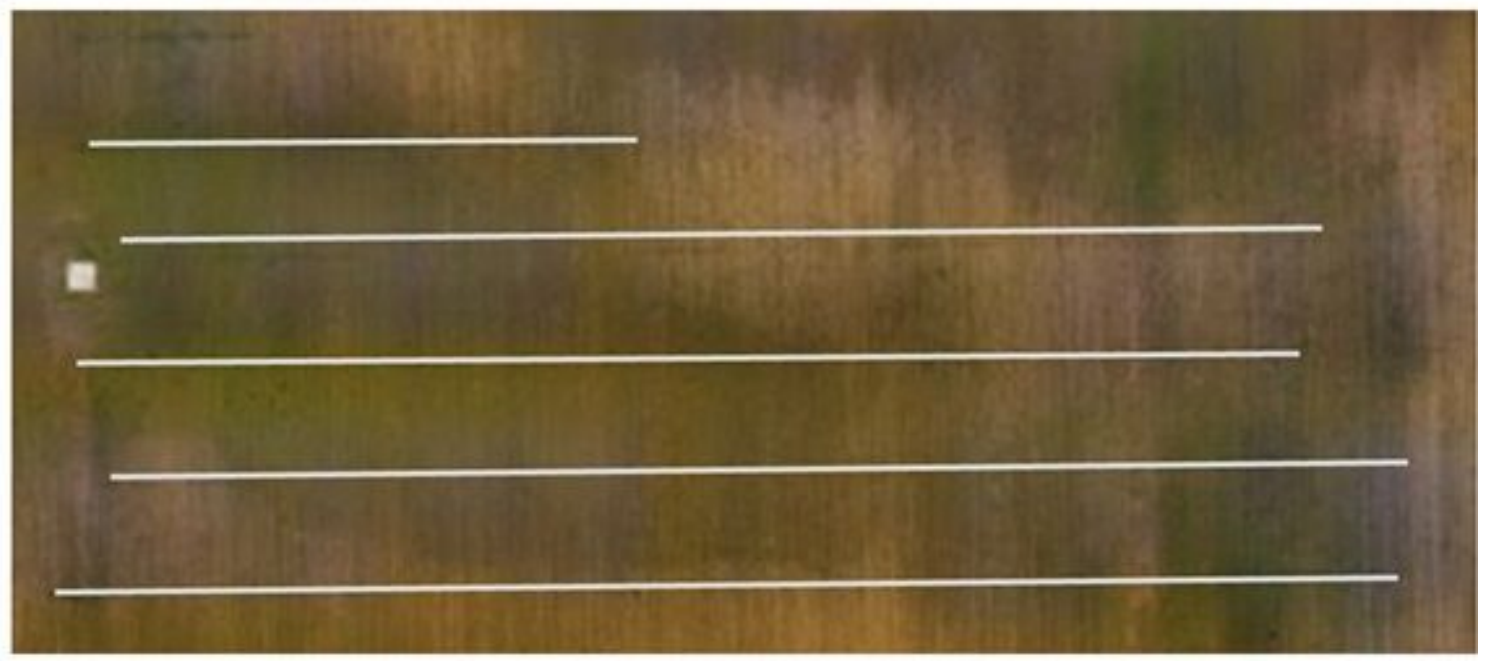

Figure 3

[a] Section of visible image with dull color linear feature interpreted as drainage tile with a parallel network [in 3 b]. The UAV used to aquire image the site is shown in [3c]
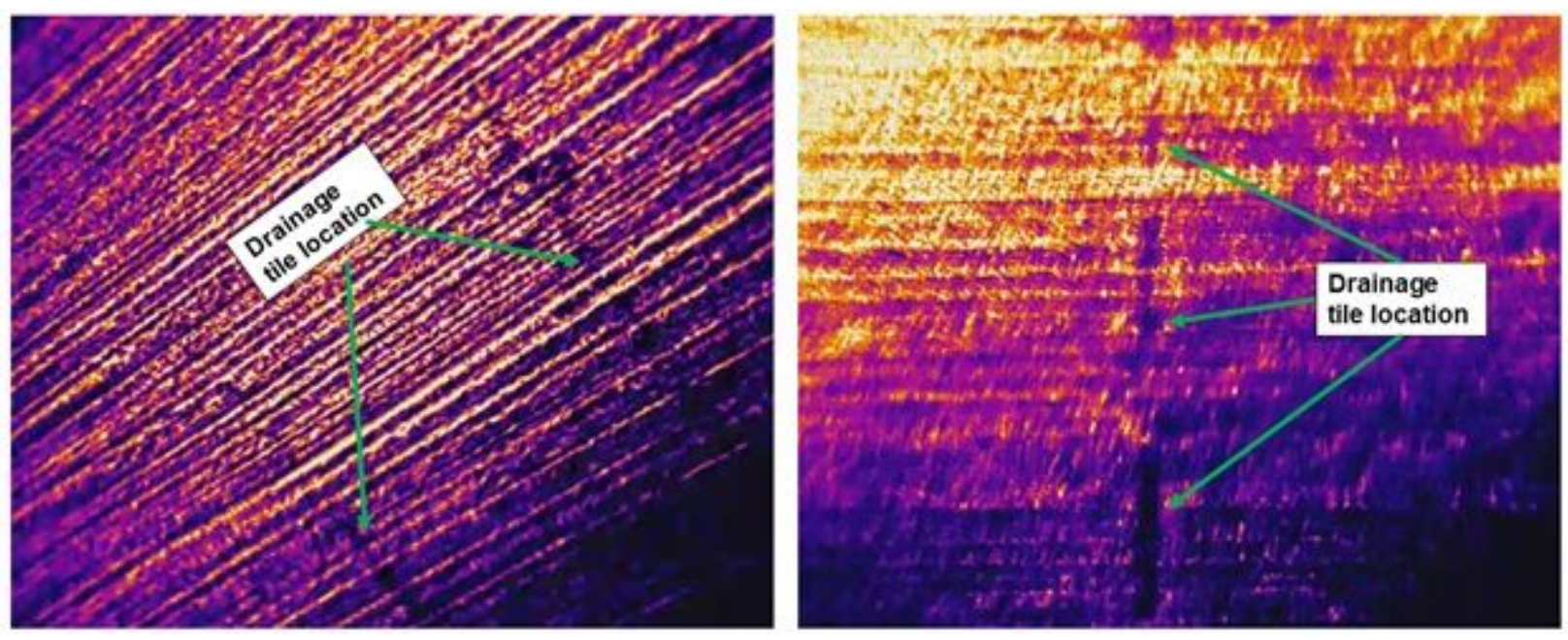

\section{Figure 4}


A section of thermal infrared images of the study site with two identified driange tile [left] and one of them imaged at a higher resolution [right].
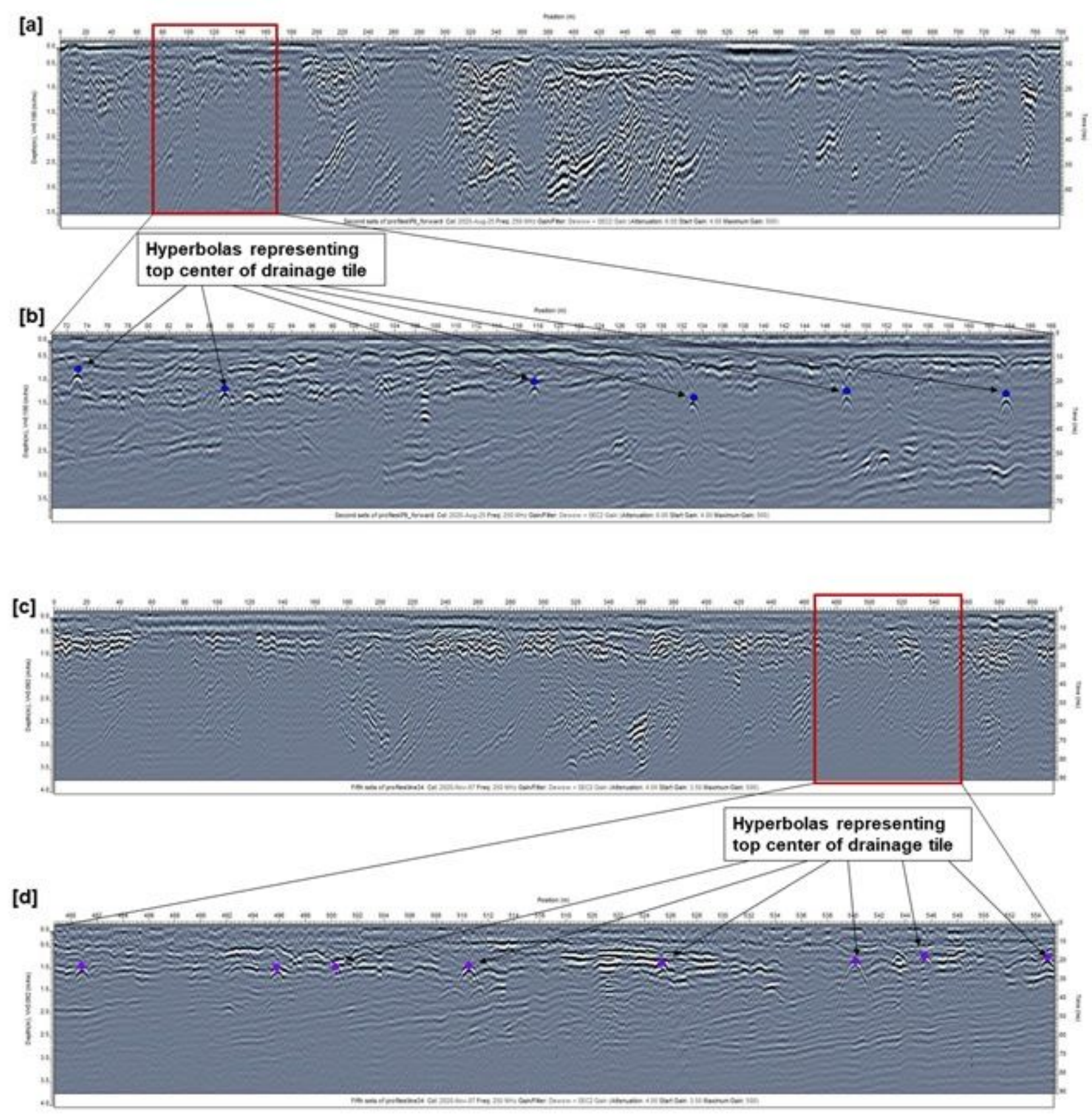

Figure 5

Selected GPR profiles ing the [a] North - South Direction and [b] East - West Direction, showing measured hyperbolas representing reflection from a point source. Point on each hyperbola represent centre point at which the transmitter and receivers cross the point object. 


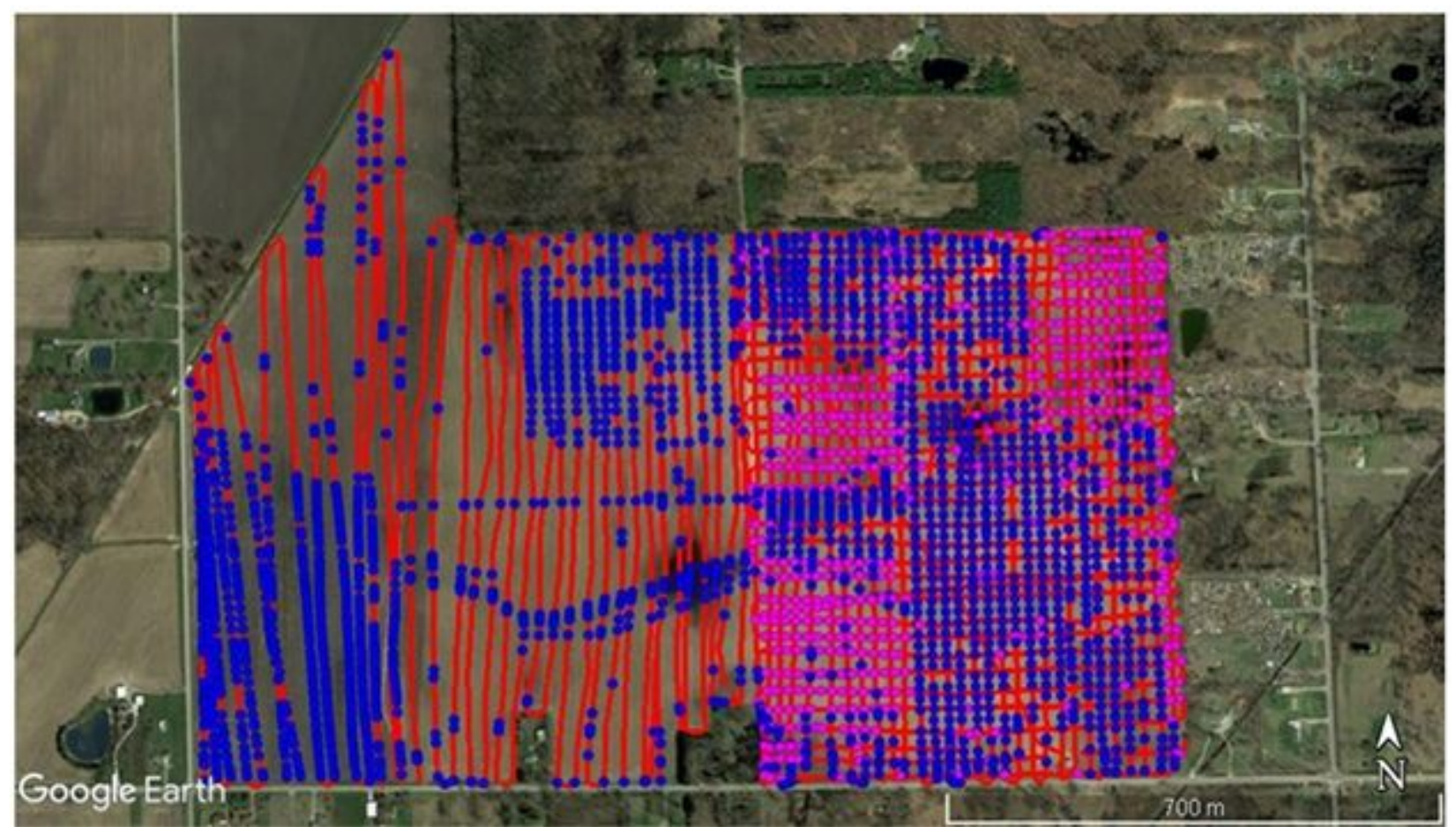

Figure 6

Picked hyperbola center point for all GPR transects overlain on a google earth map of the site (Google Earth, earth.google.com/web). Blue dots represent center of hyperbolas on North - South transect while pink dots represents those for East - West transects.

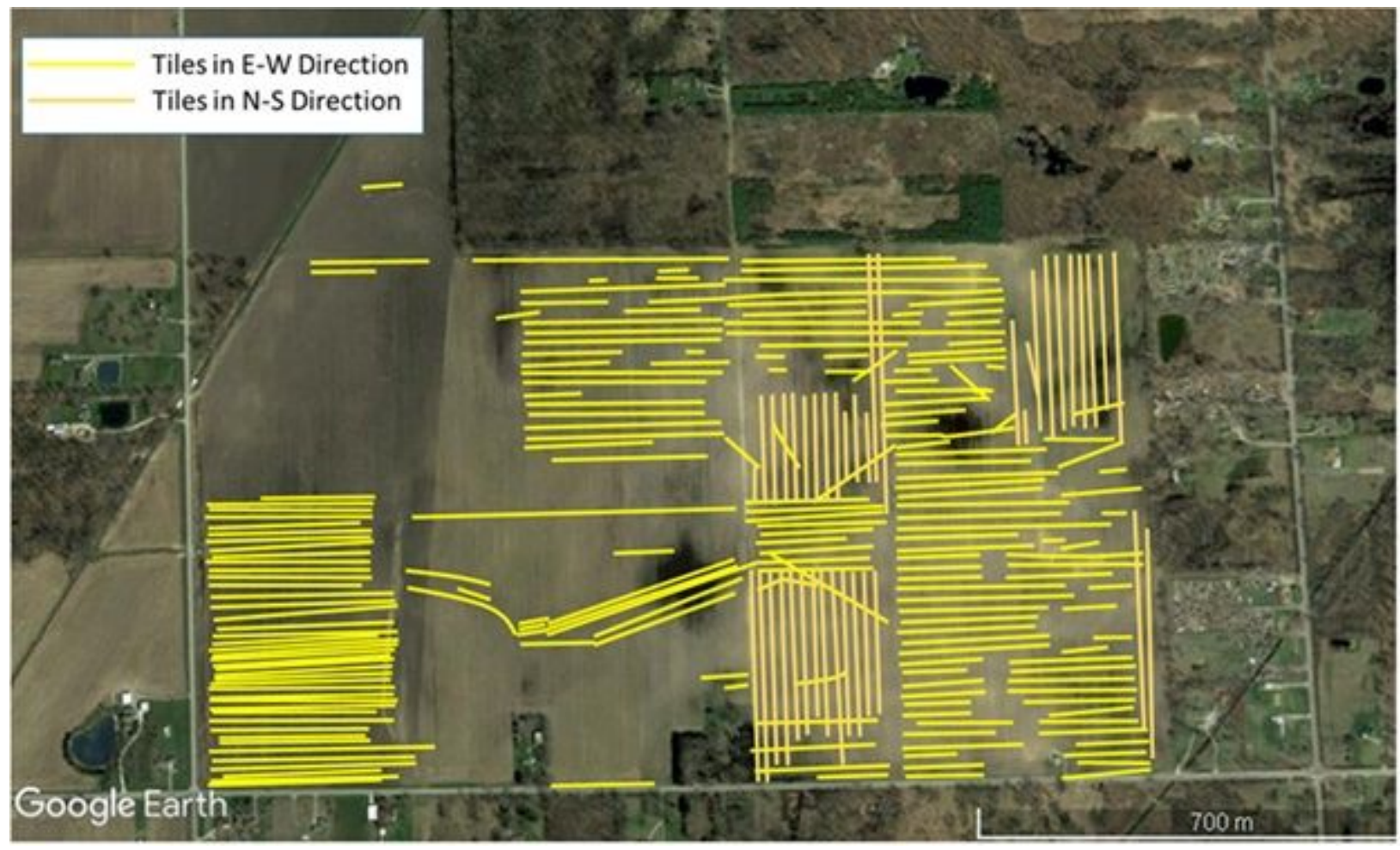

Figure 7 
Interpreted drainage tile locations overlain on google earth map of the site (Google Earth, earth.google.com/web). The lighter yellow lines indicate tiles in the E-W direction interpreted from the N-S transects while the goldenrod/orange lines indicate tiles in the N-S direction interpreted from the E-W transects.

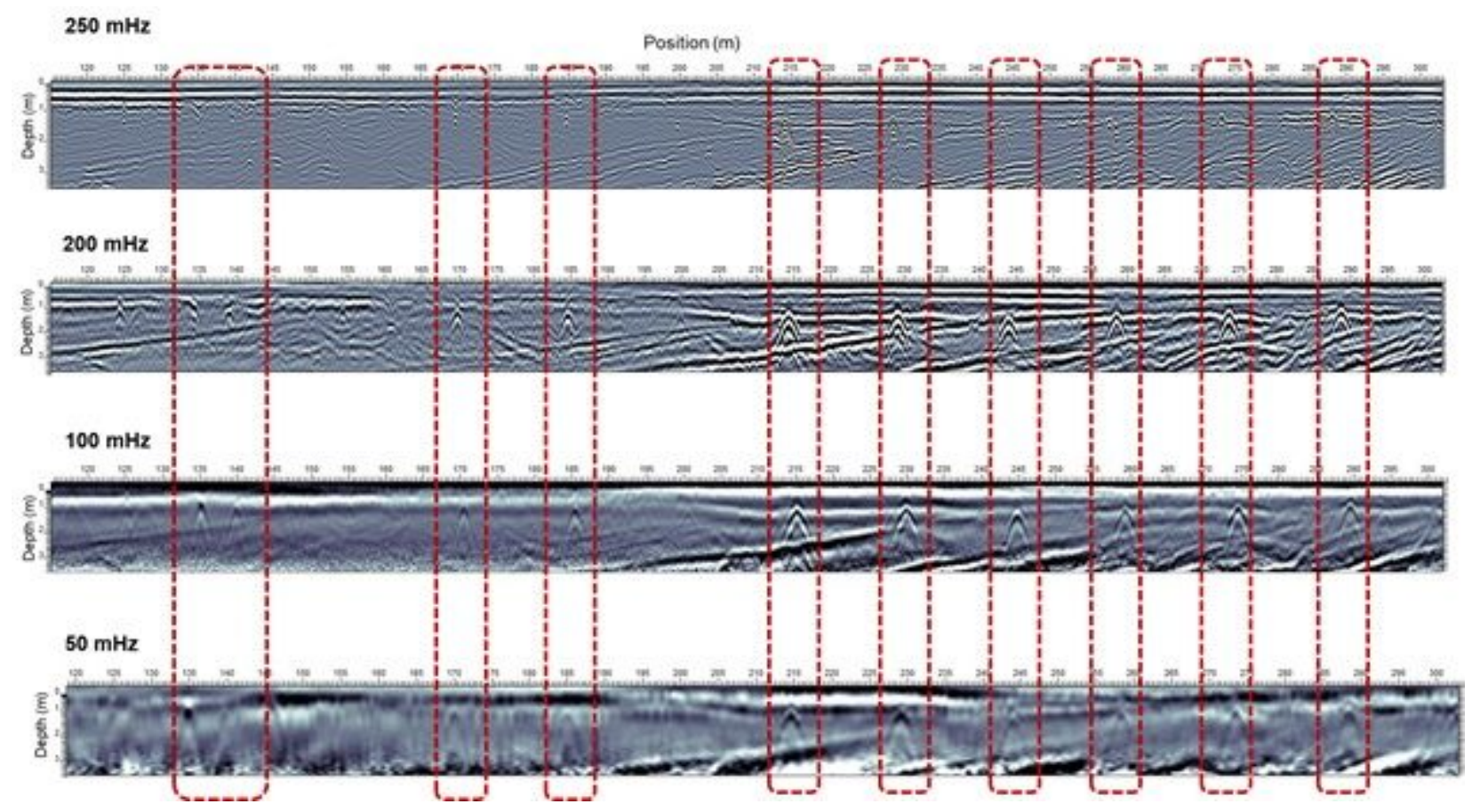

\section{Figure 8}

Comparing different signals from different antenna frequencies with $200 \mathrm{mHz}$ at the top, $100 \mathrm{mHz}$ at the middle and $50 \mathrm{mHz}$ at the bottom. Red dash-line box drawn over hyperbolas for easy comparison

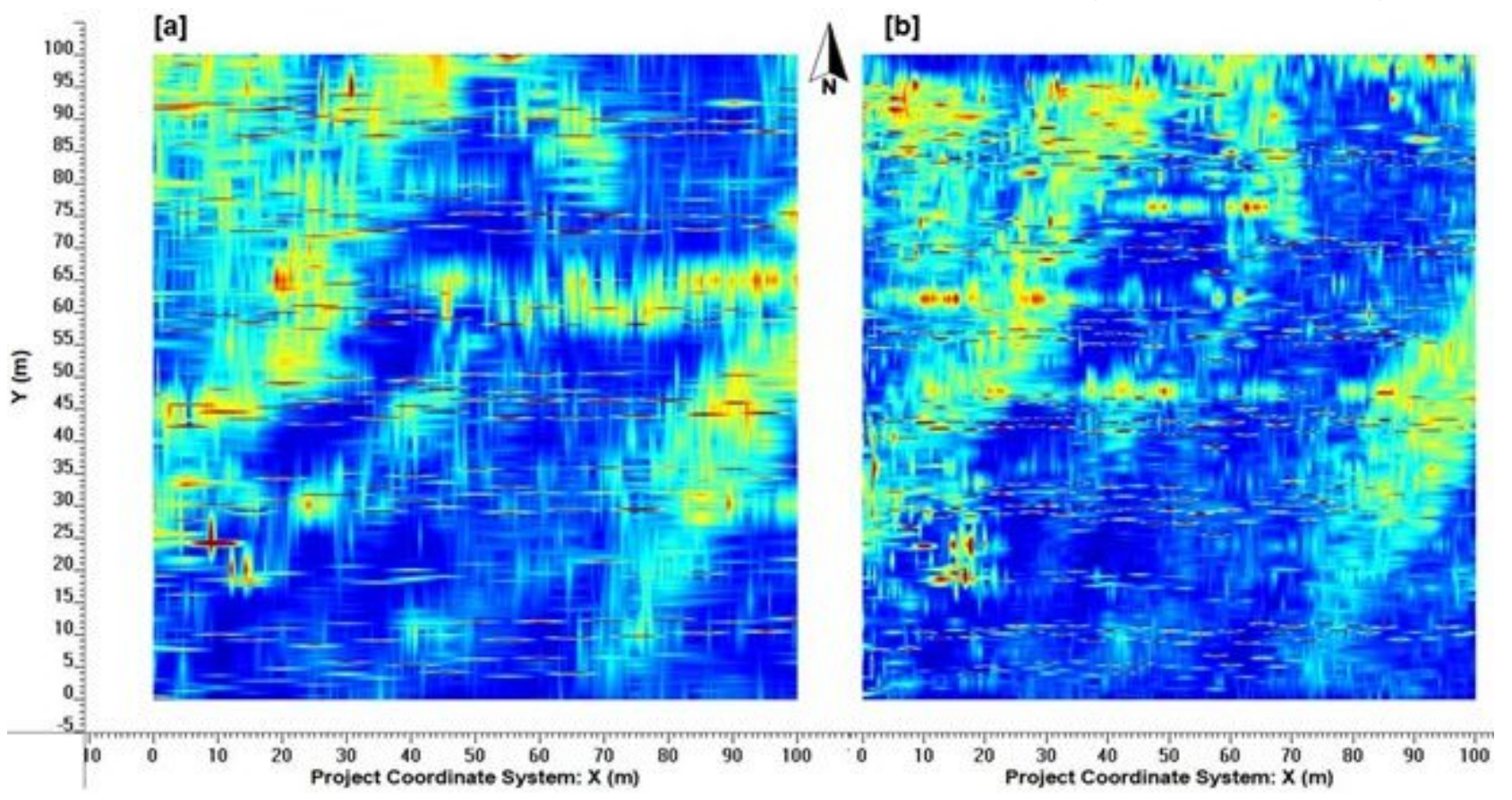

Figure 9 
GPR amplitude map of a $100 \mathrm{~m} \times 100 \mathrm{~m}$ grid at the Eastern section of the site [a] Grid acquired with $5 \mathrm{~m}$ spacing and $[\mathrm{b}] 2.5 \mathrm{~m}$ spacing. 